\title{
Our Editorial Vision
}

\author{
Michael Bernhard and Daniel I. O’Neill
}

\section{The Move to Florida}

D

erspectives on Politics is now up and running at the University of Florida. We are furiously reviewing manuscripts, commissioning book reviews, and carrying out a host of other tasks associated with editing and producing the journal. The New York journal office of our publisher, Cambridge University Press, under the leadership of Mark Zadrozny, has been immensely helpful and supportive and we look forward to a continued productive relationship with them. Barbara Walthall, APSA's Director of Publications, has been instrumental to our success in launching the journal at UF. Barbara is unfortunately retiring, and we will sorely miss her support and commitment to our success. We thank her for all she has done, and wish her all the best as she moves on to the next phase of her life.

Our immediate predecessor, Jeff Isaac, will continue to appear on the masthead of Perspectives on Politics as an editor emeritus, along with Jim Johnson and Jennifer Hochschild. Jeff leaves the journal with a sterling reputation and an important place in the life of the discipline. According to the Journal Citation Reports published by Thomson Reuters, Perspectives is presently the eighth ranked journal in the discipline with an impact factor of 3.23. ${ }^{1}$ In recognition of his contribution to the discipline, Jeff received the Frank J. Goodnow award for service at this year's annual meeting. It has been an eventful eight years for Jeff as editor, and twelve years running the book review section, and he is profoundly deserving of this recognition.

Most of the material in this issue was developed by Jeff and his team at Indiana. We oversaw the selection of offerings and production but not the full editorial process. The material published in the next issue (16:1) will be the first largely produced by the UF team. We want to express our thanks to Jeff, who was very patient and extremely generous in answering our questions and giving us a great deal of useful advice. We also want to express our thanks to his editorial team-James Moskowitz, the outgoing and indefatigable managing editor-as well as Jeff's editorial assistants: Laura Bucci, Katherine Scofield, Brendon Westler, Fathima Musthaq, Rafael Khachaturian, Rachel Gears, Peter Giordano, and Katelyn Stauffer.

As the new editors of Perspectives on Politics, it is important to stress that we embrace the mission of cultivating a "political science public sphere," a vision that the previous editors have worked so hard to create. The journal is diverse, engaging, and has increasing disciplinary impact. We proceed from the understanding that Perspectives is not broken, and thus is not in need of major repairs. Rather, our task will be to remain true to the mission and introduce incremental changes to build on its current level of success. Later in this essay we discuss one such change and we will keep you informed with further news in future issues.

\section{Maintaining and Developing the "Political Science Public Sphere"}

Since its inception under the leadership of Jennifer Hochschild, Perspectives on Politics has occupied a unique position within the discipline. When James Johnson was editor, for example, a statement entitled "Philosophy for Perspectives on Politics" featured above the masthead in each issue, describing the journal's approach and goals. It stated that its purpose was "to provide political insight on important problems, as it emerges from rigorous, broadbased research and integrative thought." From the beginning, then, the aim of Perspectives - quite unlike other scholarly outlets within political science-has always been to "enable members of different subfields to speak with one another-and with knowledgeable people outside the discipline," regarding issues of common concern. This latter group includes journalists, policy analysts, public officials and their staffs, and members of other social sciences. Subsequently, under Jeff Isaac's editorship, the journal's overarching goal was succinctly described as that of creating "a political science public sphere."

To this end, early in his tenure as editor Isaac produced a "Statement of Editorial Philosophy" which will continue to be cited on the masthead as fundamental to the "Philosophy of Perspectives on Politics." The "Statement" likewise stresses the special scholarly space the journal inhabits, as opposed to more narrowly specialized outlets, pertinently noting that "Perspectives on Politics seeks to provide a space for broad and synthetic discussion within the political science profession and the broader scholarly and reading publics." Thus, while it necessarily 
draws on and helps contribute to the scholarship featured in more specialized journals,

at the same time, Perspectives seeks to promote a complementary form of broad public discussion and synergistic understanding within the profession that is essential to advancing scholarship and promoting academic community. Perspectives seeks to nurture a political science public sphere, publicizing important scholarly topics, ideas, and innovations, linking scholarly authors and readers, and promoting broad reflexive discussion among political scientists about the work they do and why this work matters.

Hence it is clear that Perspectives on Politics is a journal with a keen self-understanding and vision. It knows where it comes from, what its distinctive goals are, and what types of scholarship further those goals. That vision informs all formats in which work appears in the journal, from the front to the back of each issue, and ranging from research articles, "reflections" essays, scholarly symposia on a single book, critical book dialogues, book review essays covering more than one similarly-themed volume, thematic book review sections that cross field-specific lines, and conventional reviews. The focus of every issue of Perspectives has been and will continue to be on innovative thinking about the big orienting questions that appropriately structure political inquiry, and problem-driven scholarly discussions. For this reason, the work that appears in its pages needs to be framed in broad terms and written in clear language that is readily accessible to scholars of all fields of political science, as well as to interested and informed people outside the discipline and even the academy itself. The journal is intentionally ecumenical and open to a wide variety of methodological and epistemological approaches and ontological orientations, with the caveat that all authors eschew excessively particularistic and esoteric jargon that speaks only to a narrow audience of specialists. This is essential to creating a more transparent, open, and interactive political science public sphere that invites engagement, rather than erecting barriers to it.

In order to remain true to the mission of the journal we will emphasize four principles in our editorial strategy. These principles will inform our decision-making on publication and our advice to authors on revision.

Addressing Important Issues. This includes addressing the burning issues of the day. Nor will we shy away from work that has strong policy implications. And we will encourage authors to consider what the ramifications of their findings are for practical politics. We also will be open to new approaches to, and innovative strategies for, addressing the enduring questions of the discipline. Finally, we will be open to work that reflexively considers the state of the discipline, its strengths and weaknesses. The "reflections" section of the journal has been important in addressing significant issues in the discipline, the changing conditions under which we work, and the relationship of political science to the public at large. While these contributions are more essayistic in nature, they contribute something unique to the journal and the self-understanding of the discipline.

Pluralism. We are fully committed to continuing the pluralism of the journal in its many dimensions. We will be open to both scientific and humanistic approaches to the study of politics. The same holds for methodology. We will be open to established and novel forms of making quantitative, qualitative, and experimental inference, as well as research that uses multiple and mixed methods. Of course, we are committed to publishing the highest quality work without regard to approach and method, and thus will retain stringent standards of peer review. We will endeavor to publish only work of the highest quality irrespective of the specie in which it plies its trade. However, whatever the approach or method, we will demand from authors that the final product be presented in a form that allows it to reach the broadest possible audience. As a disciplinary flagship, Perspectives has to be open to all subfields and specializations of political science. This will remain our goal not only in article selection but in the management of the book review section as well. Finally, we will endeavor to publish work that represents the population of the discipline in all its diverse aspects. On this score, the journal has a relatively strong record and this is something we aim to continue and improve in absolute terms. ${ }^{3}$ Our commitment to academic pluralism will help ensure that the pages of Perspectives will be broad and inclusive in terms of the authorship of its articles.

Cross-field Dialogue. The accessibility of the presentation of findings by the journal helps to promote cross-field dialogue by exposing the wider community of scholars to work in other fields in a readily accessible manner. This helps scholars identify research relevant to their interests, and encourages the cultivation of deeper understandings of debates outside of one's own specialization. Not only will we publish broadly from all major subfields in the discipline, but another fashion in which we can promote a political science public sphere is finding novel ways to get members of different subfields and specializations to engage with each other. Here we see the grouping of articles and book reviews from across fields that address related problems in special sections as another key facet of the journal's promotion of cross-field dialogue.

Outreach beyond the Discipline. Part of the essential mission of Perspectives is to make the insights generated by political scientists more accessible to a wider audience interested in politics. One crucial purpose of creating a political science public sphere is to put the discipline in the national public sphere to an even greater extent. We have moved beyond the period when there was a general malaise in the discipline about the paucity of impact that political science research had on public discourse. The proliferation of online sources has given many political 
scientists a voice in the public sphere to an extent not seen before (e.g., The Monkey Cage, 538, and OpenDemocracy, just to name a few of the places political science has staked out an influential web presence). Still, one is more likely to see an economist, an ex-military officer, or a historian on a public affairs show than a political scientist. An essential part of our mission is to continue to raise the profile of the discipline to the public at large.

\section{What's on the Agenda in this Issue?}

The thematic focus in this issue is "Problems of the State in the Developing World." Five different articles address this issue from a variety of perspectives. The state and its sovereignty is one of the central areas of inquiry in the discipline that spans domestic and international politics, and thus we have a nice mix of articles in comparative politics and international relations.

Alison Post, Vivian Bronsoler, and Lana Salman examine "Hybrid Regimes for Local Public Goods Provision." In the age of neoliberalism, non-state actors have taken an increased role in the provision of public goods globally. The authors develop a framework that incorporates both states and non-state actors into the discussion of public goods provision. By taking into account whether the state directly or indirectly supplies public goods and the degree of state penetration in society, they theorize four different patterns of public goods provision. This is illustrated with empirical material on water supply, public transportation, and sanitation in Africa, Asia and Latin America.

Nicholas Barnes addresses the central Weberian problem of the monopoly of the state on the legitimate use of violence in "Criminal Politics: An Integrated Approach to the Study of Organized Crime, Politics, and Violence." As a field, conflict studies has paid limited attention to organized crime, but Barnes argues that given the increasing death tolls it produces, it is time to take it more seriously. In the past this exclusion was based on the fact that criminals were not interested in taking power or seceding. However, in exploring ways in which organized crime has come to collaborate and compete with the state, he argues that a fundamental reconceptualization is in order.

Alisha Holland and Ben Ross Schneider address the problem of the state and provision of public goods in "Easy and Hard Redistribution: The Political Economy of Welfare States in Latin America." They argue that the 2000s represented a period in which it was easy for Latin American states to create more expansive welfare states that reached more deeply into society than earlier contributory social-insurance systems. However, they argue that the period of these easy gains is over, and illustrate this with casework on unemployment benefits in Chile and housing policy in Colombia.

Roxanne Euben addresses central issues of how nonstate actors aspiring to establish state power try to reconfigure notions of state sovereignty and legitimacy in "Spectacles of Sovereignty: ISIS Executions, Visual Rhetoric, and Sovereign Power." Through an in-depth analysis of the symbolism of beheading videos, Euben uncovers a narrative that inverts power relations between the United States and ISIS' self-declared caliphate. She shows how the videos convey a message to their intended audience that the United States is the "true rogue" state and cast the caliphate as a lawful and legitimate sovereign power.

Finally, Tom Pepinsky challenges the notion of the state and its subnational administrative organization as the fundamental unit of analysis in the comparative study of subnational politics in his discussion of "Regions of Exception." He argues that regions have distinct histories and social structures that have important influences which demand explicit attention in research. Using examples from Southeast Asia, he demonstrates how this affects issues such as civil conflict, economic development, political opposition, and the viability of the nation-state. In doing so he challenges the way that we have traditionally made inference in the subnational turn in comparative politics.

The second section in this issue brings together two articles on institutional change in the United States. Eric McGhee and Boris Shor look at the attempts to reduce polarization in American politics by the adoption of open primary systems that eliminate the role of parties in selecting the top two candidates for the general election. In "Has the Top Two Primary Elected More Moderates?" they examine the impact of such reforms in California and Washington. The results are ambiguous, with the moderating effect seemingly stronger in the former, but probably enhanced by the simultaneous switch to a system of independent redistricting. The findings raise questions about how much the US can reduce the current cycle of polarization through institutional reform.

Finally, Scott Lemieux examines the balance of power between the branches of government in "Is the United States a Regime of Judicial Supremacy?” He suggests that the notion of judicial supremacy has emerged because other branches of government have found it useful to empower the judiciary. This raises the issue of whether the other branches have the ability to take away what they have granted. If this is the case, does judicial sovereignty really capture the regime in the United States? He probes this question by examining a series of cases where the courts were unable to settle constitutional debates.

\section{Our First Innovation: Limited FirstView Publication}

Due to its thematic focus, the publication of each issue of Perspectives has an event-like quality. This has been one of the hallmarks of the journal and one which we find 
attractive and unique. At the same time, there is a professional expectation to participate in the early publication of articles online. There is also evidence that this increases an article's impact, something that authors appreciate. To accommodate these concerns we will begin to make limited use of FirstView on Cambridge Core to post some articles to the journal's website.

However, when we develop thematic sections that endow individual issues with a unique character, we will continue the policy of not posting the individual works on-line as they are readied in the editorial process. This would detract from their impact as a whole. We will continue to hold these articles as a group and feature them thematically as we have in the past, making the publication of each issue (hopefully) a significant event. For other content it makes sense to publish with greater speed. The McGhee and Shor and the Lemieux articles in this issue were thus the first that Perspectives has published on FirstView. We will therefore continue to release portions of the content of each issue in this way while holding our thematic core for conventional release. In individual cases we will also be flexible to the needs of particular authors. We hope that this new policy preserves one of the unique features of the journal while simultaneously meeting the needs of our authors and the discipline in a flexible fashion.

\section{Notes}

1 Thompson Reuters 2017.

2 Isaac 2010.

3 Teele and Thelen 2017, 436.

\section{References}

Issac, Jeffrey C. 2010. "Statement of Editorial Philosophy." Perspectives on Politics 8(1): 7-10.

Teele, Dawn and Kathleen Thelen. 2017. "Gender in the Journals: Publication Patterns in Political Science." PS: Political Science \&o Politics 50(2): 433-47.

Thompson, Reuters. 2017. "InCites Journal Citation Reports_Political Science.” Accessed August 5, 2017. https://jcr.incites.thomsonreuters.com/JCRJournalHomeAction.action?SID = B2-ySuxxEm7DQxxb-

N7a4UqSmyvJeBASSxxC9CN-

18x2dAfd4DDv8mlfXs0XqhOfBNgx3Dx3Dtxx-

L5egxxKJFryulII5n4y8Ax3Dx3D-

YwBaX6hN5JZpnPCj2lZNMAx3Dx3Djywguyb6iMRLFJm7wHskHQx3Dx3D\&SrcApp=IC2LS\&Init $=$ Yes 


\section{Statement of Mission and Procedures}

Perspectives on Politics seeks to provide a space for broad and synthetic discussion within the political science profession and between the profession and the broader scholarly and reading publics. Such discussion necessarily draws on and contributes to the scholarship published in the more specialized journals that dominate our discipline. At the same time, Perspectives seeks to promote a complementary form of broad public discussion and synergistic understanding within the profession that isessential toadvancing scholarship and promoting academic community.

Perspectives seeks to nurture a political science public sphere, publicizing important scholarly topics, ideas, and innovations, linking scholarly authors and readers, and promoting broad reflexive discussion among political scientists about the work that we do and why this work matters.

Perspectives publishes work in a number of formats that mirror the ways that political scientists actually write:

Research articles: As a top-tier journal of political science, Perspectives accepts scholarly research article submissions and publishes the very best submissions that make it through our double-blind system of peer review and revision. The only thing that differentiates Perspectives research articles from other peer-reviewed articles at top journals is that we focus our attention only on work that in some way bridges subfield and methodological divides, and tries to address a broad readership of political scientists about matters of consequence. This typically means that the excellent articles we publish have been extensively revised in sustained dialogue with the editor-me-to address not simply questions of scholarship but questions of intellectual breadth and readability.

"Reflections" are more reflexive, provocative, or programmatic essays that address important political science questions in interesting ways but are not necessarily as systematic and focused as research articles. These essays often originate as research article submissions, though sometimes they derive from proposals developed in consultation with the editor in chief. Unlike research articles, these essays are not evaluated according to a strict, doubleblind peer review process. But they are typically vetted informally with editorial board members or other colleagues, and they are always subjected to critical assessment and careful line-editing by the editor and editorial staff.

Scholarly symposia, critical book dialogues, book review essays, and conventional book reviews are developed and commissioned by the editor in chief, based on authorial queries and ideas, editorial board suggestions, and staff conversations.

Everything published in Perspectives is carefully vetted and edited. Given our distinctive mission, we work hard to use our range of formats to organize interesting conversations about important issues and events, and to call attention to certain broad themes beyond our profession's normal subfield categories.

For further details on writing formats and submission guidelines, see our website at http://www.apsanet.org/ perspectives/ 